\title{
o Programa Mais Médicos do Governo Federal: Um aporte pedagógico na saúde para a construção da cidadania.
}

RESUMO: O presente artigo trata da celeuma que a implementação da política pública - Programa Mais Médicos - do Governo Federal, causou quando do seu início. Partindo de um contexto histórico do SUS - Sistema Único de Saúde - se analisam a repercussão na mídia e sociedade, bem como entrevistas de representantes da classe médica, governamentais e da própria população, fazendo também um aporte pedagógico do programa como facilitador ao ingresso do médico brasileiro formado no exterior, no mercado de trabalho do país, mediante Exame Revalida.

Palavras-Chave: Educação. Saúde. Programa Mais Médicos.Revalida.PolíticaPública.

ABSTRACT: This article deals with the stir that the implementation of public policy - Program More Doctors- the Federal Government, caused when it starts. From a historical context of the NHS - Health System - analyzing the impact in the media and society as well as interviews with representatives of the medical, governmental class and population, also making a pedagogical contribution of the program as a facilitator of admission of the medical Brazilian formed outside, in the labor market of the country, through examination revalidate .

Keywords: Education.Health. Program More Doctors. Revalidate.PublicPolicy.

\section{INTRODUÇÃO}

O Programa do Governo Federal Mais Médicos, é uma política pública destinada à melhoria do Sistema Único de Saúde com a previsão de mais investimentos em infraestrutura das unidades de saúde e dos hospitais e ainda levar mais médicos para áreas remotas e de periferia onde há escassez de profissionais. Sua finalidade principal além de expandir o número de vagas de medicina e de residência médica para o aprimoramento da formação médica no Brasil é, dar um reforço no atendimento à atenção básica de municípios com maior vulnerabilidade social e Distritos Sanitários Especiais Indígenas. O baixo número de médicos por habitantes no Brasil que é de 1,8 médicos por habitante, e a falta de médicos brasileiros em quantitativo para atender as demandas populacionais, principalmente em áreas remotas e de periferia, levou o governo brasileiro a convocar médicos de outras nacionalidades e de brasileiros formados fora do Brasil, sem que houvesse a necessidade 1 Professora da SEDF, mestre em Ciência Política na linha de pesquisa em Direitos Humanos minorias civis. 
de fazer o exame do revalida, burlando norma do Conselho Federal de Medicina e Ministério da Educação. Tal atitude por parte do governo causou protestos e críticas tanto da classe médica, como de outros seguimentos sociais, inclusive da imprensa. O que não se levou em conta foi o fato de que,o programa além de resolver um problema emergencial, contribui pedagogicamente como porta de entrada de brasileiros formados em medicina em outros países, dando thes a oportunidade de ao mesmo tempo em que estudam para a prova do revalida, serem automaticamente inseridos no mercado de trabalho. Com ganhos sociais tanto para a população que necessita do atendimento em atenção básica nas áreas de periferia/remotas, como para o brasileiro recém-formado em medicina no exterior, que tem a oportunidade de ingressar no mercado de trabalho de forma imediata à conclusão de sua formação.

\section{BREVE HISTÓRICO DA SAÚDE NO BRASIL COLÔNIA E IMPÉRIO}

A saúde no Brasil foi a princípio organizada como sanitária, espelhando-se na metrópole. Os serviços de saúde eram subordinados ao exército de Portugal, na figura do cirurgião-mor e o físico-mor, que estavam encarregados do saneamento e da profilaxia das doenças epidêmicas, assim como do trabalho dos médicos e profissionais da área, farmacêuticos, boticários e até curandeiros. As autoridades locais eram as responsáveis pelas questões relacionadas à higiene, tendo às câmaras municipais a função de zelar pela limpeza das cidades, fiscalizar os portos e o comércio de alimentos. A população solicitava "a presença de médicos, mediante cartas ao rei”; já naquela ocasião cobrando da autoridade governamental providências para resolução de questões da saúde pública, "apesar da dificuldade de serem encontrados profissionais dispostos a migrarem para o Brasil”. (PAIM, 2009:25-26)

A dificuldade da falta de profissionais de saúde no Brasil, principalmente de médicos, é um problemas que tem origem desde o Brasil colônia. Em 1543 foi fundada a primeira Santa casa, em Santos, por Brás Cubas, tendo esta, a finalidade de dar assistência aos pobres, indigentes e doentes. As famílias ricas recorriam aos militares, os seus cuidados. (PAIM, 2009:26)

No início do século XIX após a família real chegar ao Brasil, a partir de 1828 a municipalidade passou a assumir a responsabilidade pela saúde pública; o serviço de inspeção dos portos passou a ser da alçada do Ministério do Império, e em 1850 em função da febre amarela no Rio de Janeiro, criou-se a junta de Higiene Pública. Foi feita uma nova reforma nos serviços sanitários durante o Império, criou-se a Inspetoria Geral de Higiene, Inspetoria Geral de Saúde dos Portos e um Conselho Superior de Saúde Pública. A partir de então, o governo imperial passou a ter uma atuação maior na área de saúde da população, adotando inclusive as "primeiras medidas voltadas para a higiene escolar e para a proteção de crianças e adolescentes no trabalho das fábricas". (PAIM, 2009:26)

Diante de epidemias, a ação comunitária organizava-se, no nível local, em comissões formadas a cada episódio de saúde relevante ou por intermédio da câmara de vereadores. Mas quando a 


\section{$37 / /$}

situação se complicava, a opção era pela concentração das decisões no governo central. Assim, ao final do Império, era rudimentar e centralizada a organização sanitária brasileira, incapaz de responder às epidemias e de assegurar a assistência aos doentes, sem discriminação. (PAIM, 2009:27)

Os mais abastados contratavam médicos particulares e os mais pobres eram tratados nas casas de misericórdia, mediante a filantropia. A responsabilidade passou a ser do Estado com a proclamação da República em 1889.

Durante a passagem do século XIX para o XX, início da industrialização do Brasil, a saúde despontava como questão social, ou seja, como um problema que não se restringia ao indivíduo, exigindo respostas da sociedade e do poder público. (PAIM, 2009:27)

Na República Velha (1889-1930), a organização dos serviços de saúde era confusa, o que existia era uma espécie de não-sistema de saúde, com omissão do poder público, "uma concepção liberal de Estado de que só cabia a este intervir nas situações em que o indivíduo sozinho ou a iniciativa privada não fosse capaz de responder.”(PAIM, 2009:27-28)

A necessidade de uma tomada de decisão e resolução dos problemas relacionados à saúde, não apenas como questão de higiene e sanitarismo, fez com que a sociedade passasse a exercer uma maior pressão e cobrança ao poder público. Medidas se fizeram necessárias para que toda a população, e não apenas uma parcela, "a dos mais abastados", tivessem acesso à medicina. A saúde passa dessa forma a ser "um problema" de Estado.

\section{UM POUCO DA HISTÓRIA DO SISTEMA ÚNICO DE SAÚDE BRASILEIRO (SUS)}

Na República Velha não havia um Ministério da Saúde, ao invés do problema da saúde no Brasil ser tratado por um órgão ligado à saúde, era tratado como caso de polícia, lembrando uma operação militar em caso de campanhas, denominando seus idealizadores de polícia sanitária. Devido à pressão dos trabalhadores vinculados aos fundos de previdência, as caixas de aposentadoria e pensões (CAPs), a partir de 1923, esses trabalhadores passaram a ter assistência médica.

O sistema público de saúde no Brasil nasceu pela via da saúde pública, medicina previdenciária e medicina do trabalho. Inicialmente a população ofereceu resistência às intervenções autoritárias por parte do governo relacionadas às campanhas sanitárias, tendo como exemplo à famosa "revolta da vacina", na cidade do Rio de janeiro, onde a população ofereceu resistência e foi necessário empregar o uso da força policial para a vacinação, que equivocadamente pensava-se que a vacina era um método de extermínio da população mais pobre pelo governo. Sanitaristas formados nos Estados Unidos mudaram o paradigma da coerção, para a persuasão. O Ministério da Saúde foi instituído em 1953. Com a criação do Ministério da Saúde o combate a algumas doenças teve serviços específicos e centralizados. 
O tipo de saúde pública para combater epidemias, não tinha integração com a medicina previdenciária nos Institutos de Aposentados e Pensionistas (IAPs), e nem com a saúde do trabalhador, sendo, portanto a saúde no Brasil tratada de forma fragmentada.

\footnotetext{
[...] a organização dos serviços de saúde no Brasil antes do SUS vivia em mundos separados: de um lado, as ações voltadas para a prevenção, o ambiente e a coletividade, conhecidas como saúde pública; de outro, a saúde do trabalhador, inserida no Ministério do Trabalho; e, ainda, as ações curativas e individuais, integrando a medicina previdenciária e as modalidades de assistência médica liberal, filantrópica e, progressivamente, empresarial. (PAIM, 2009:31)
}

As doenças passavam a modificar o seu caráter, do predomínio de doenças relacionadas à pobreza, para doenças crônicas e degenerativas e os traumas. Com o desenvolvimento industrial no governo $\mathrm{JK}$, outros ramos ligados à medicina começaram a emergir, tais como o farmacêutico e de equipamentos, fortalecendo a assistência médico-hospitalar e enfraquecendo a saúde pública. Aparece, a medicina de grupo,que "constituía um tipo de empresa médica que prestava serviços a uma grande empresa industrial ou de serviço, mediante pré-pagamento", contando com incentivos do governo, que dispensava parte da cobrança de impostos; sendo que os governos militares ainda diminuíram os recursos destinados à saúde. Cada vez mais a saúde da população deteriorava, onde, antes de 1975 o orçamento do Ministério da Saúde não alcançava 1\% dos recursos públicos da área federal. (PAIM, 2009:32-33)

Desde a passagem da década de 1940 para a de 1950, a assistência médico-hospitalar cresceu e ampliaram-se os serviços médicos próprios dos IPAs, além dos convênios e contratos da previdência com os hospitais particulares e beneficentes. A prática médica passava por profundas transformações, de sorte que o exercício liberal da medicina ia sendo substituído por vínculos empregatícios dos médicos com o poder público e com empresas. Desenvolvia-se a medicina empresarial e tecnológica. (PAIM, 2009:34)

Nos governos militaresprevaleceu à opção de comprar serviços médico-hospitalares do setor privado, para atender os segurados da previdência, dando início a política conhecida como privatização, que em seu bojo trouxe consigo as práticas de corrupção: epidemias de cesarianas, internações de mendigos em hospitais psiquiátricos particulares e até cirurgias ginecológicas em homens e outras aberrações.

Ao longo do século XX manteve-se ao lado dos três vieses da saúde no Brasil: a saúde pública, a medicina previdenciária e a saúde do trabalhador, - a medicina liberal -, caracterizada por "uma ampla autonomia do médico, que definia o preço da consulta, local e horário de atendimento em seu consultório particular". Mas devido ao aumento dos custos e necessidade de utilização de equipamentos, "o médico viu reduzida a sua autonomia, mesmo em seus consultórios com regras estabelecidas". Estava, portanto atrelado ao mercado e sujeito a normas desse mercado, não tendo autonomia para definir valores e ficando a mercê de decisões dos convênios e conveniados, sendo a medicina liberal aos poucos substituída pela medicina empresarial. Esses dois últimos modelos de 
medicina também tinham um concorrente que era a medicina filantrópica praticada por instituições que remontam ao século XVI, que recebiam liberação de impostos por parte do governo para continuarem a manter seus atendimentos. (PAIM, 2009).

Desde 1988 não há mais indigentes, nem serviços gratuitos prestados por caridade. Todos os serviços de saúde prestados por essas instituições são remunerados pelo SUS e financiados pela sociedade, por meio de impostos diretos e indiretos, além de contribuições. (PAIM, 2009:37)

Dessa forma, a saúde desde 1988 passou a ser política exclusiva do Estado. Onde de fato, a nossa jovem Constituição Federal apesar de garantir em seu artigo Art. 196: a saúde como direito de todos e o Estado tendo como dever garanti-la mediante políticas públicas visando reduzir risco de doenças e outros agravos de forma universal e igualitária, na prática, nem sempre é o que acontece, pois os noticiários mostram diariamente situações de verdadeiro caos na saúde pública brasileira e má prestação de serviços. A rede de Casas de Misericórdia perdeu sua razão de ser à medida que seus serviços prestados são pagos com grande atraso pelo Governo - naturalmente mais interessado na promoção de órgãos públicos.

O que deveria ser o gozo do direito à saúde, passa a ser em alguns casos necessária a intervenção do poder judiciário para garantir internações em UTIs, exames mais específicos ou remédios de alto custo. Em alguns casos o paciente não consegue vencer o tempo de espera e acaba por ir a óbito. Às vezes, na recepção da unidade de saúde ou dentro do pronto socorro, deitado até mesmo no chão, antes dos primeiros atendimentos. Protestos são realizados como forma de pressionar o governo, sem muito sucesso, apesar das garantias constitucionais existentes.

\section{A ATUAL CONJUNTURA DA SAÚDE NO BRASIL: A MEDICINA COMTEMPORÂNEA}

Notícias jornalísticas nos dão conta do caos diário que se encontra a saúde no Brasil: dois pacientes após sofrerem um traumatismo craniano e dirigirem-se a hospitais públicos em busca de atendimento pelo Sistema Único de Saúde (SUS) tiveram a negativa ao atendimento.

\footnotetext{
[...] Médicos de plantão informaram às famílias sobre a situação crítica e recomendaram paciência. Nos dois hospitais públicos, as unidades de terapia intensiva estavam lotadas. Inconformados, os parentes recorreram à justiça, que expediu ordens para internação imediata. Os médicos se recusaram a retirar pacientes de UTIs para abrir as vagas exigidas. Após o ocorrido um oficial de justiça apareceu nos hospitais com escolta policial e mandados de prisão contra os médicos. Eles não foram encontrados. Cenas assim viraram rotina. A crise no sistema público de saúde, do qual dependem oito entre dez brasileiros, está no topo das prioridades do eleitorado. Pesquisas anteriores às eleições de 2014 demonstraram segundo o Ibope, que a maioria da população (60\%), considera a saúde o maior problema nacional. (O GLOBO, 2014).
}

O momento atual em comparação com aquele de antes da criação do SUS, encontra-se, não, um caso de polícia como no início do século XX, mas um caso a ser tratado via judicial. Como mostra a reportagem jornalística. 
O médico se torna impotente diante da falta de leitos e infraestrutura nos hospitais e postos de saúde espalhados pelo Brasil inteiro, que se traduzem em grande parte em casos de judicialização, conforme relatado na reportagem do jornal.

Se por um lado faltam investimentos e medidas emergenciais para resolver o problema da saúde pública, por outro lado, a escassez de profissionais na área médica também é apontada pelo governo como entrave para a resolução do problema.

Contudo, o Conselho Regional de Medicina de São Paulo declara que a questão não é a falta de profissionais, pois o Brasil está a um passo de chegar ao quantitativo de 400 mil médicos, atingindo a taxa de dois profissionais por grupo de mil habitantes. Informa ainda que nos últimos 42 anos, o total de médicos no país cresceu 557,7\%, enquanto que a população em geral aumentou 101,8\%, a razão médico/habitante também apresentou crescimento significativo. Gerando um acréscimo de sete a oito mil médicos por ano.

De um lado o governo aponta a falta de profissionais para o exercício da medicina e principalmente a negativa desses médicos em trabalhar em áreas de periferia e áreas remotas, por outro lado os médicos acusam o governo de não possibilitar-lhes, tanto condições favoráveis em termos de infraestrutura nas unidades de saúde públicas, quanto à falta de um plano de carreira para a área médica, fazendo com que os profissionais existentes não se sintam atraídos para o exercício da medicina, de acordo com as carências existentes.

Após avaliação por parte do governo da necessidade de medidas emergenciais que resolvessem o problema do caos na saúde, uma das medidas tomadas, foi à importação de médicos estrangeiros ou a aceitação de brasileiros formados no exterior, sem que houvesse a necessidade de prestar o Exame do Revalidada, exigido por todo e qualquer médico formado no estrangeiro, para que possa exercer a medicina e credenciar-se junto aos Conselhos de medicinaespalhados pelo Brasil.

O Governo Federal criou então, o Programa Mais Médicos, através de uma Medida Provisória (MP n ${ }^{\circ}$ 621, de 8 de julho de 2013) e de Portaria Interministerial (Saúde e Educação, publicada no mesmo dia sob o $\mathrm{n}^{\mathrm{o}} 1.369$, e posteriormente, a Medida Provisória foi convertida em Lei $\left(\mathrm{n}^{\mathrm{o}}\right.$ 12.871, de 22 de outubro de 2013). O Programa em questão foi criado para aumentar o número de médicos em regiões com maior carência desses profissionais, fortalecendo a prestação de serviços de atenção básica e aprimoramento da formação médica no país. A medida do governo foi recebida de forma bastante crítica pela classe médica brasileira, criando uma série de debates entre os órgãos governamentais competentes, Congresso Nacional, representantes da classe médica e a sociedade civil, maior interessada essa última, em resolver a situação já que, acaba sendo a parte mais prejudicada pelo impasse.

Após fazer uma análise de conjuntura da atual situação da saúde pública no Brasil e voltando ao tempo da criação do Sistema Único de Saúde (SUS), passaremos a discorrer sobre o atual Programa Mais Médicos, fazendo uma análise quanto ao Exame do Revalida. Quais os benefícios do ponto 


\section{$41 / /$}

de vista pedagógico, o Programa do Governo Federal, favorece aos médicos brasileiros formados no estrangeiro?

A segunda parte da análise faz uma contextualização do atual cenário da medicina no Brasil e faz considerações sobre a questão do Programa Mais Médicos. Que, cumpre além de um atendimento mais abrangente (áreas remotas e periferias), também serve como mecanismo de porta de inserção no mercado de trabalho dos médicos recém-formado no exterior em curso de medicina. Cujo médico ao retornar ao Brasil, entra no mercado de trabalho de forma imediata.

Nos três anos de contrato do médico estrangeiro ou brasileiro recém-formado no exterior para atuar no Programa Mais Médicos, oportuniza-se de forma concomitante estudar e atuar na área médica, e a junção sistemática da teoria e prática. Sendo que desta feita, o aspirante ao revalida vislumbra lograr maior êxito na prova (exame do revalida), valendo-se de ter garantido o direito ao exercício da medicina de forma livre em qualquer parte do território nacional.

\section{O MODELO DE CURRÍCULO DOS CURSOS DE MEDICINA NO BRASIL}

Após modificações no currículo dos cursos de medicina no Brasil ao longo do processo de sua consolidação, o Ministério da Educação-MEC, juntamente com o Ministério da Saúde-MS, órgãos responsáveis de forma conjunta pela formação dos médicos no Brasil, adotam medidas para mudanças substanciais no currículo.

O MEC dá autonomia para o respectivo colegiado do curso, decidir se adotará a modalidade seriada anual, ou semestral, sistema de créditos ou modular, mas coloca algumas diretrizes a serem cumpridas pelos cursos de modo a imprimir qualidade nos mesmos.

Algumas das diretrizes são diretamente voltadas ao SUS e principalmente à promoção da saúde de indivíduos como direitos a serem resguardados pelo Estado. Desse modo o curso de graduação em medicina deverá:

_ Ter como eixo do desenvolvimento curricular as necessidades de saúde dos indivíduos e das populações referidas pelo usuário e identificadas pelo setor saúde;

_ Utilizar metodologias que privilegiem a participação ativa do aluno naconstrução do conhecimento e a integração entre os conteúdos, além de estimular a interação entre o ensino, a pesquisa e a extensão/assistência;

_ Incluir dimensões éticas e humanísticas, desenvolvendo no aluno atitudes evalores orientados para a cidadania;

_ Promover a integração e a interdisciplinaridade em coerência com o eixo de desenvolvimento curricular, buscando integrar as dimensões biológicas, psicológicas, 
sociais e ambientais; inserir o aluno precocemente em atividades práticas relevantes para a sua futura vida profissional;

_ Utilizar diferentes cenários de ensino-aprendizagem permitindo ao aluno conhecer e vivenciar situações variadas de vida, da organização da prática e do trabalho em equipe multiprofissional;

- Propiciar a interação ativa do aluno com usuários e profissionais de saúde desde o inicio de sua formação, proporcionando ao aluno lidar com problemas reais, assumindo responsabilidades crescentes como agente prestador de cuidados e atenção, compatíveis com seu grau de autonomia, que se consolida na graduação com o internato;através da integração ensino-serviço vincular a formação médicoacadêmica as necessidades sociais da saúde, com ênfase no SUS. (MEC, 2015).

Alguns cursos como o da PUC Minas Gerais, que se destacam como proposta inovadora e boa avaliação junto ao MEC têm como princípio em seu Projeto Político Pedagógico, a preparação do profissional não apenas para o conhecimento das técnicas, mas também para atividades que humanizem a medicina.

Ao adotar o paradigma da integralidade, o curso forma um profissional de saúde com visão global do ser humano, apto a trabalhar em equipes multiprofissionais e em redes de atenção a saúde, comprometido com a qualidade e humanização do atendimento prestado aos indivíduos, famílias e comunidades.

Coerente com o seu objetivo de formar médicos generalistas para atender as necessidades de saúde da população e com perfil profissional aderente à estratégia de reorganização da atenção à saúde no Brasil a partir da Atenção Primária o Curso de Medicina da PUC Minas em Betim terá como foco privilegiado da formação do médico as unidades que constituem a rede local de atenção à saúde do SUS no município de Betim. (PPP-PUC, MG: 2014).

O Projeto Político Pedagógico tomado como exemplo já na formação do graduando em medicina privilegia uma relação de proximidade tanto da teoria/prática, quanto do vínculo com o SUS, prestando atendimento ao público próximo a escola de medicina. Dando ao futuro médico uma formação de maior qualidade e vivência das carências enfrentadas pela população e ao dirigirse ao SUS, coloca a qualidade do profissional, em maior destaque com relação à quantidade de profissionais.

Percebe-se por parte do governo uma preocupação com a qualidade da formação de médicos de forma a fazer uso de uma estratégia pedagógica que faça a junção sistemática da teoria com a prática. E ainda percebe-se a ênfase que é aludida ao SUS, formando profissionais que possam atender as reais necessidades do usuário do sistema único. 
Esse método de ensino que prioriza uma graduação em parceria com o SUS, proporciona benefícios muito grandes, tanto para o graduado em medicina, quanto para o cidadão que se utiliza do sistema. Uma vez que juntar de forma imediata o aprendizado teórico com o prático, proporciona qualidade à formação do profissional inseridonessa lógica. A população também tem no aumento de profissionais, mesmo que em regime de aprendizagem, um número maior de oferta dos serviços de atendimento à atenção básica.

Dessa forma, as alterações no currículo dos cursos de medicina no Brasil em consonância com o SUS oferecem de imediato aumento da demanda de profissionais para o atendimento à atenção básica, proporciona maior qualidade na formação médica e distribuição de médicos em hospitais com maiores demandas de ausência de profissionais.

\section{A SAÚDE E A EDUCAÇÃO COMO PROCESSO DE AFIRMAÇÃO DA CIDADANIA NO BRASIL}

O Processo de afirmação da Cidadania no Brasil é dotado de uma enorme complexidade, pelo próprio signo linguístico da palavra "processo", algo que está em andamento, em construção, portanto inacabado. Dissertar sobre este assunto se torna complicado no sentido de escolher por qual viés abordá-lo, já que a construção da cidadania passa por três eixos: direitos civis, políticos e sociais (CARVALHO, 2001:9). Na análise que se faz do Programa do Governo Federal Mais Médicos, será feito um contraponto com a educação, por entender que ambos são direitos civis, de caráter político e ambos com grande impacto no social.

Após o fim da ditadura militar, em 1985, o esforço de construção da democracia no Brasil foi se delineando e a palavra "cidadania", assumiu contorno e lugar de destaque entre políticos, jornalistas, intelectuais, líderes sindicais, dirigentes de associações e simples cidadãos, todos a adotaram. No auge desse delineamento a palavra Cidadania, acabou ganhando status de pessoa, e ao invés de dizerem: "o povo quer isto ou aquilo", dizia-se "a cidadania quer", dessa forma "Cidadania virou gente", e no "auge do entusiasmo cívico, chamamos a Constituição de 1988 de Constituição Cidadã”. (CARVALHO, 2001:7)

\footnotetext{
[...]o fenômeno da cidadania é complexo e historicamente definido. O exercício de certos direitos, como a liberdade de pensamento e o voto, não gera automaticamente o gozo de outros, como a segurança e o emprego. O exercício do voto não garante a existência de governos atentos aos problemas básicos da população. Dito de outra maneira: a liberdade e a participação não levam automaticamente, ou rapidamente, à resolução de problemas sociais. Isto quer dizer que a cidadania inclui várias dimensões e que algumas podem estar presentes sem as outras. Uma cidadania plena, que combine liberdade, participação e igualdade para todos, é um ideal desenvolvido no Ocidente e talvez inatingível. Mas ele tem servido de parâmetro para o julgamento da qualidade da cidadania em cada país e em cada momento histórico.
}

Tornou-se costume desdobrar a cidadania em direitos civis, políticos e sociais. O cidadão pleno seria aquele que fosse titular dos três direitos. Cidadãosincompletos seriam os que possuíssem 
apenas alguns dos direitos. Os que não se beneficiassem de nenhum dos direitos seriam não cidadãos. (CARVALHO, 2001:8-9).

Entende-se que para uma sociedade afirmar sua cidadania se faz necessário um grande esforço conjunto. Para Carvalho, o cidadão será considerado pleno, e não incompleto ou até mesmo "não cidadão", quando forem equalizados em um mesmo bojo, os direitos civis, políticos e sociais. Essa equação não é simples, não se faz de um dia para o outro, e por ser "processo", o - caminho é longo - como afirma Carvalho.

Já temos as normas positivadas naCarta Constitucional de 1988, com pouco mais de duas décadas. Ela por si só, não nos conduz a cidadania. Se fazê-la, foi um trabalho árduo e difícil, forjado na luta e no esforço de toda a sociedade em seus diferentes seguimentos juntamente com o legislativo, colocá-lana prática é tarefa ainda mais árdua.

Eis onde reside o problema, efetivar na prática a Constituição é exatamente o que deve ser feito. Alguns opinam que se faz necessário elaborar mais Leis. Ora vejam, se as que já estão positivadas e não são efetivadas, elaborar outras tantas, resolveria a questão? Acredita-se que não. E para tanto é bastante plausível defender que um dos caminhos a serem trilhados é o caminho da Educação, aquele que inclui o indivíduo no contexto da política, tornando-o apto à prática de seus direitos e deveres civis, com uma consequente inclusão social, já que a educação contribui em grande medida para a inclusão e mobilidade social.

Neste caso, em específico, a educação voltada para a formação de profissionais em medicina. Sendo que, o número de escolas de cursos de formação na área de medicina é insuficiente para a demanda necessária de médicos que possa suprir as carências da população, principalmente em áreas remotas, de ribeirinha e periferias de grandes centros urbanos.

Nessa parte da análise, contextualiza-se o atual cenário da medicina no Brasil e tece considerações sobre a questão do Programa mais médicosque,cumprindo além de um atendimento mais abrangente (áreas remotas e periferias), também cumpre papel de abertura e inserção no mercado de trabalho dos médicos (as) brasileiros (as) recém-formados no exterior em curso de medicina. Sendo estes últimos, quando de seu retorno ao Brasil, se inserem no mercado de trabalho imediatamente.

Nos três anos de contrato para atuar no Programa Mais Médicos, o recém-formado estuda/ atua na área médica, e na junção sistemática da teoria e prática, vislumbra maior êxito na prova do Exame do Revalida, valendo-se posteriormente da garantia do direito ao exercício da medicina de forma livre em qualquer parte do território nacional.

Torna-se importante salientar que inicialmente o objetivo do Programa Mais Médicos, não está centrado na inclusão ou facilitação dos brasileiros formados no exterior, mas que ao cumprir seu objetivo maior de ofertar atendimento de saúde em atenção básica à população, culmina em incluir os brasileiros formados em medicina no exterior. Já que, o número de oferta de vagas em curso de 
medicina no Brasil não atende as demandas atuais.

Apesar de inicialmente a preocupação do governo não ter sido centrada em atender essa outra demanda de cidadãos e cidadãs, que buscam acesso à formação em medicina fora do país, é possível fazer uma relação com o Programa Mais Médicos. Nesse sentido, através de um viés em consonância com a pedagogia, que atrela uma boa formação em qualquer área do conhecimento, à concomitância da teoria à prática. Vislumbrando-se no Programa, essa junção, com benefícios positivos ao gozo da cidadania e inclusão de cidadãos e cidadãs.

\section{CONSIDERAÇÕES FINAIS}

O trabalho em conjunto, na área da educação com a área da saúde proporciona benefícios ao brasileiro graduado no estrangeiro.Ao entrar no Programa de Governo Mais Médicos obtendo contrato de três anos, sem necessidade imediata de prestar o Exame Revalida, tem a oportunidade de juntar a teoria/prática adquirida no estrangeiro, com a vivência da realidade brasileira.

Ao invés do recém-formado voltar simplesmente ao seu país com uma graduação em medicina, esse profissional através do Programa Mais médicos, vislumbra a possibilidade imediata de inserção no mercado de trabalho. Enquanto vivencia a realidade brasileira, prepara-se para o Exame do Revalida aumentando as suas chances de sucesso no mesmo. E, ainda supre as carências de médicos em áreas de periferia e remotas, onde os médicos já devidamente credenciados para o exercício da medicina no país, não querem atuar.

Vale lembrar que uma vez o médico sendo aprovado pelo Exame do Revalida, o mesmo passa a ter direito ao exercício da medicina em qualquer parte do país, inclusive em centros urbanos onde o número de médicos por habitantes é maior.

Uma das estratégias do governo ao elaborar o Programa, foi justamente para levar médicos a áreas com menores índices de profissionais médicos por habitantes, em algumas localidades com índice na casa do zero ou negativos. Ao mesmo tempo, o governo tratou de aumentar o número de oferta de vagas nos cursos de medicina, principalmente em cidades do interior e áreas mais distantes dos grandes centros. Locais estes últimos com número maior de profissionais da área médica.

Se, os esforços por parte do governo trarão resoluções imediatas para o caos da saúde no Brasil ${ }^{2}$ já sabemos que não. Principalmente em se tratando de estratégias diretamente ligadas à educação, pois esta última se faz de forma processual, uma vez iniciada, há que, continuar empreendendo

2 A pesquisa Situação de Saúde da População Brasileira: Perfil Sócio demográfico, Epidemiológico, Fontes de Financiamento e Demanda Acolhida por Regiões e Municípios, coordenada pelo Departamento de Gestão da Educação na Saúde do Ministério da Saúde, (DEGES/MS), apresenta, entre outras possibilidades: aumentar capacidade instalada em saúde, em municípios de 100 a 300 mil habitantes, que são polos regionais e promover a formação e capacitação de profissionais de saúde, especialmente médicos, e incentivar sua presença nas regiões com maiores carências como a Norte e a Nordeste. Fonte: http://www.portalmedico.org.br/include/biblioteca_virtual/abertura_escolas_medicina/007. htm. Acesso em 30 set. 2015. 
esforços, mas também, que aguardar o tempo.

É sabido que existe um grande número de jovens brasileiros cursando medicina em outros países vizinhos como Argentina, Bolívia e Paraguai, e ainda em outros mais distantes, como Cuba e Rússia, devido a convênios tanto pelo Mercosul, como em outros formatos pelo governo brasileiro.

O jovem brasileiro estudante de medicina no estrangeiro, uma vez vencendo a primeira barreira que é a conclusão do curso lá fora, ao retornar ao país ainda tem uma segunda barreira a ser vencida, que é passar no Exame Revalida, feito em parceria com o MEC, MS e Conselho Federal de Medicina. Uma vez tendo permanecido fora do Brasil por pelo menos seis anos, inúmeras são as barreiras para a sua aprovação, inclusive com a língua mãe, já que os cursos são em outros idiomas, como o espanhol e o inglês.

O ingresso desse jovem em um Programa como o Mais Médicos passa a ser bastante atrativo para o retorno desse jovem ao Brasil, tendo em vista que o seu diploma em medicina já é válido no país de sua formação, e fora do Brasilas oportunidades são vantajosas. Mas, em alguns casos a vontade de retorno ao seu país de origem é muito grande, sendo que, há de conciliar benefícios próprios. Neste quesito, se houver alguma contrapartida por parte do governo brasileiro, uma das possibilidades de aumentar o número de médicos no Brasil, seria via formação no exterior.

A junção teoria e prática valendo-se de metodologia que aproxima a instituição formadora do futuro médico com o SUS, e no caso do recém-formado no estrangeiro, a oportunidade de familiarizar-se com o SUS, via ingresso no Programa Mais Médicos, pode trazer benefícios conjuntos para o governo, para o jovem brasileiro formado no estrangeiro, e para a população em geral, melhorando e aprimorando o atendimento na saúde pública brasileira.

Após analisar o Programa Mais Médicos do ponto de vista pedagógico com vantagens ao SUS como um todo, infere-se que, se não há solução imediata para o caos na saúde brasileira, medidas alternativas de caráter pedagógico na formação de profissionais, possibilitariam uma alternativa de resolução.Sendo queo Programa Mais Médicos atuaria também, como mecanismo de inclusão do brasileiro graduado em medicina no exterior.

\section{REFERÊNCIAS BIBLIOGRÁFICAS}

PAIM, Jairnilson Silva. O que é o SUS. Rio de Janeiro: Editora Fiocruz, 2009.

CARVALHO,José Murilo de. Cidadania no Brasil: o longo caminho. Rio de Janeiro: Civilização Brasileira, 2013.

Sites:

$<$ http://www.ambitojuridico.com.br/site/index.php?n_link=revista_artigos_leitura\&artigo_ 
id=10912> Acesso em 12 nov.2014.

$<$ http://portalsaude.saude.gov.br/index.php/cidadao/acoes-e-programas/mais-medicos $>$ Acesso em 25 out.2014.

$<$ http://oglobo.globo.com/brasil/crise-na-saude-torna-judiciario-segunda-porta-de-acesso-aosus-14223837\#ixzz3JqNw9OOo> Acesso em 22 nov.14.

$<$ http://www.cremesp.org.br/?siteAcao $=$ CentroDados\&acao=detalhes_capitulos\&cod_ capitulo=32> Acesso em 22 nov. 14 .

$<$ http://oglobo.globo.com/brasil/crise-na-saude-torna-judiciario-segunda-porta-de-acesso-aosus-14223837\#ixzz3JqNw9OOo> Acesso em 22 nov.14.

$<$ http://www.cremesp.org.br/?siteAcao $=$ CentroDados\&acao=detalhes_capitulos\&cod_ capitulo $=32>$ Acesso em 22 nov.14.

$<$ http://www.pucminas.br/medicina/projeto.pdf $>$ Acesso em 24 nov.14.

$<$ http://portal.mec.gov.br/cne/arquivos/pdf/Med.pdf $>$ Acesso em 24 nov.14.

$<$ http://www.portalmedico.org.br/include/biblioteca_virtual/abertura_escolas_medicina/007. htm>. Acesso em 30 set. 2015

Artigo apresentado em 15-09-15

Artigo aprovado em 17-11-15

Artigo publicado no sistema em 30-12-15 